\title{
BLACKOUT POETRY: \\ UMA POÉTICA DO CORTE COMO RASURA
}

http://dx.doi.org/10.11606/issn.2237-1184.v0i24p78-93

Vinicius Carvalho Pereira

Universidade Federal do Mato Grosso (UFMT)

RESUMO

O presente artigo discute a poética do corte perpetrada por Austin Kleon no seu projeto de blackout poetry, em que poemas experimentais são produzidos a partir da rasura de notícias de jornal. Apresentando similaridades com a proposta de Tristan Tzara no último manifesto dadaísta, os poemas em blecaute põem em questão uma produção artística que se dá por excisão, e não por adição, o que subverte os paradigmas mais tradicionais de interpretação de textos literários.

\section{ABSTRACT}

This paper discusses the poetics of cutting, carried out by Austin Kleon within his blackout poetry project, wherein experimental poems are produced by scratching news from newspapers. Similarly to what Tristan Tzara proposed in the last dada manifest, blackout poems put at stake a kind of art made by excision, instead of addition, which subverts the most traditional paradigms for interpreting literary texts.
PALAVRAS-CHAVE:

blackout poetry.

Corte.

Rasura.

poesia experimental.

KEYWORDS:

blackout poetry.

cutting.

Scratching.

experimental poetry. 


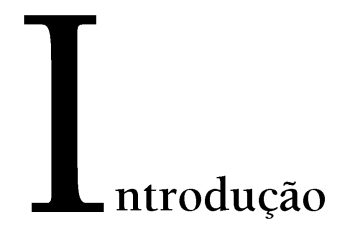

Recortes e colagens, como operações de transtextualização, não são novidade no cenário literário ocidental. Largamente explorados a partir das poéticas de vanguarda do início do século XX, os contrabandos textuais com tesoura e cola têm seu lugar na história da literatura eternizado por Tristan Tzara e sua "Receita para fazer um poema dadaísta" no último manifesto Dadá (Manifesto sobre o amor fraco e o amor amargo), lido em Paris em 1920.

As ações de recortar e colar foram também reapropriadas pela teoria literária e pela crítica de arte em geral como operadores lógicos dos jogos intertextuais a que boa parte das obras da segunda metade do século XX e do início do século XXI se dedicam. Assim, em torno dessa metáfora do retalhamento, teorias da intertextualidade e da significação se desenvolveram no pós-estruturalismo francês, como as que orientam a discussão de Compagnon $^{1}$ em O trabalho da citação (2007), cujo primeiro capítulo já se intitula "Tesoura e cola"; ou como as noções de talho e enxerto, caras à teorização sobre escrita e différance em Derrida² (1972).

Disso se nota que as operações intertextuais de recorte não são novas nem pouco estudadas no âmbito das pesquisas literárias, seja do ponto de vista dos objetos de análise, seja das teorias que embasam a crítica. Por outro lado, bem mais escassas são as discussões acerca da poética do corte, em oposição ao termo cognato "recorte", entre os quais o presente artigo propõe uma distinção conceitual, ainda que os dicionários tratem ambos os substantivos como sinônimos em uma série de contextos.

Por "recorte" entende-se aqui a excisão a tesoura, a fim de separar algumas extensões da superfície recortada para reuso alhures; nesse contexto, a matriz de onde são recortadas as partes é deixada de lado (ao menos materialmente) quando do que se faz posteriormente com os retalhos. Por sua vez, toma-se neste artigo "corte" como termo polissêmico, morfológica e semanticamente ligado ao "recorte", mas ultrapassando-lhe os sentidos. Isso porque, além de talho, o corte pode também ser um processo de cancelamento, anulação ou rasura, quando se corta, a caneta, uma palavra de um texto.

\footnotetext{
${ }^{1}$ COMPAGNON, Antoine. O trabalho da citação. Belo Horizonte: UFMG, 2007.

2 DERRIDA, Jacques. Margens da filosofia. Lisboa: Rés, 1972.
} 
Esse é o procedimento que marca a poética de Austin Kleon, jovem artista reconhecido no mercado editorial norte-americano pelo que chamou de blackout poetry ("poesia do blecaute", em tradução livre para o português). Seu best seller Newspaper Blackout (KLEON $\left.{ }^{3}, 2010\right)$ reúne 152 poemas, cada um deles composto a partir de um recorte (a tesoura) diferente de jornal. De posse do pedaço recortado da página do jornal, Kleon deliberadamente corta (a caneta ou pincel atômico) a maior parte da superfície textual, cobrindolhe a tinta frases, palavras ou letras. O resultado dessa pilhagem gráfica são superfícies quase completamente enegrecidas (donde se entende o nome de blackout poetry), nas quais se leem apenas os grafemas, vocábulos ou sinais de pontuação que não foram riscados. Estes formam poemas que não se podem dizer escritos por Kleon; são, na verdade, produto de operações de apagamento por meio da rasura.

Ao tomar como fenômeno estético a ser analisado a poética do corte, interessa neste artigo pensar o rendimento estético da arte de Kleon, que se faz por gataruja: rasura não só metafórica, como já analisado em vários estudos sobre paródia ou pastiche, mas rabisco que materialmente encobre, ou anula, porções do texto primeiro.

\section{A rasura como projeto}

No prefácio de Newspaper Blackout, o autor narra em tom anedótico como começou a produção de seus poemas em blecaute. Segundo tal relato, desde a graduação Kleon sonhava em se tornar escritor de contos. Durante o curso, conseguia produzir, motivado pelas demandas acadêmicas e pelos workshops de escrita criativa; contudo, finda a graduação, deparou-se com um bloqueio criativo: "I struggled through handbooks of writing exercises. Nothing worked. Each blink of the Microsoft Word cursor taunted me" (KLEON, 2010, p.xiv).

Ainda segundo esse relato, a namorada do autor recortava diariamente, para fins profissionais, matérias de jornais sobre sua área de atuação, deixando as partes que não lhe interessavam amontoadas próximo à escrivaninha de Kleon. Inicia-se, então, o seu projeto (termo por ele mesmo usado ao se referir à blackout poetry) quando, munido de um pincel atômico preto, começou a cobrir uma série de palavras nos recortes de jornais, deixando apenas algumas à mostra, sem saber bem por que o fazia: "All I knew was that it was fun to watch those words disappear behind that fat black marker line. It didn't feel like work. It felt like play" (KLEON, 2010, p.xiv).

\footnotetext{
${ }^{3}$ KLEON, Austin. Newspaper Blackout. New York: Harper Perennial, 2010.
} 
A um primeiro olhar, as noções de projeto e acaso, marcantes na anedota contada pelo autor no prefácio da obra, podem parecer contraditórias, uma vez que, por projeto, entende-se algo minimamente programático, e não aleatório. No entanto, o contrassenso se desfaz se observado o quão frequente no mercado editorial norte-americano de best sellers é a narrativa do autor desenganado pela falta de ideias, o qual acaba por descobrir seu ofício por acaso (epifania, sussurro da musa ou acúmulo de jornais sobre a mesa) e faz dele um projeto literário de sucesso em termos de vendas.

Tais informações ganham ainda mais relevância na análise que aqui se pretende se considerarmos que Kleon, depois da publicação de seu livro, criou um blog com milhares de acessos e teve num curto espaço de tempo três outros best sellers publicados - Steal Like an Artist (KLEON ${ }^{4}$, 2012), Show Your Work (KLEON 5 , 2014) e The Steal Like an Artist Journal: A Notebook for Creative Kleptomaniacs $\left(\mathrm{KLEON}^{6}, 2015\right)$-, todos eles de caráter motivacional sobre criação e criatividade. Ademais, hoje o autor é palestrante sobre criatividade na era digital, falando para membros de grandes conglomerados de comunicação de massa, como Pixar, Google, SXSW, TEDx, e The Economist (KLEON $\left.{ }^{7}, 2016\right)$.

A despeito do forte apelo mercadológico, que frequentemente deixa desconfortável a crítica acadêmica, a blackout poetry é um fenômeno literário do século XXI que requer estudos pormenorizados, seja pelo vasto alcance de sua produção, seja pelas inovações que ela enseja no plano da materialidade textual.

Quanto à rápida e ampla difusão do gênero, há que se considerar que em 2010, dois anos depois do lançamento da primeira edição impressa de Newspaper Blackout, Kleon criou um blog para divulgação de seus poemas, que atualmente conta com mais de 140.000 leitores de todo o mundo, muitos dos quais também enviam para o site seus próprios poemas em blecaute (KLEON, 2016). Para fomentar a produção de seus leitores, Kleon opera mais um engenhoso jogo de recorte e colagem, bem ao gosto da intertextualidade inerente a essas práticas com tesoura e cola: numa seção ao final do livro, deixa ele uma receita para produção de poemas em blecaute, reeditando o manifesto dadaísta:

Grab a newspaper.

\footnotetext{
${ }^{4}$ KLEON, Austin. Steal Like an Artist: 10 Things Nobody Told You About Being Creative. New York: Workman Publishing Company, 2012.

${ }^{5}$ KLEON, Austin. Show Your Work!: 10 Ways to Share Your Creativity and Get Discovered. New York: Workman Publishing Company, 2014.

${ }^{6}$ KLEON, Austin. The Steal Like an Artist Journal: A Notebook for Creative Kleptomaniacs. New York: Workman Publishing Company, 2015.

${ }^{7}$ KLEON, Austin. Austin Kleon's Website. 2016.

Disponível em <http://austinkleon.com/newspaperblackout/>. Acesso em $07 \mathrm{dez} 2016$.
} 
Grab a marker.

Find an article.

Cross out words, leaving behind the ones you like.

Pretty soon you'll have a poem. (KLEON, 2010, p.157)

Além da óbvia semelhança na hibridação entre os gêneros receita e manifesto, perpetrada por Tzara e Kleon, destaca-se a igualdade no ingrediente comum a ambas as receitas: o jornal. Em adição a isso, subjacente à proposta dadaísta e ao projeto da blackout poetry (guardadas as devidas proporções entre uma vanguarda que influenciou os rumos da arte no século XX e a produção de um autor de best seller no século XXI) está o pressuposto de que qualquer pessoa pode fazer um poema. Talvez porque, em ambas as concepções, não se trate de escrever um poema, e sim de revelar, por meio do (re)corte, um poema que já existe em estado de potência - seja no "reino das palavras/Lá estão os poemas que esperam ser escritos", conforme dissera Drummond, ou na página de classificados ou esportes de um jornaleco local, conforme feito por Kleon e analisado na próxima seção do presente artigo.

\section{O corte como procedimento de rasura}

A fim de melhor

Figura 1: "The Skinny Son" Fonte: Kleon $(2010$, p.61)

compreender como se opera a

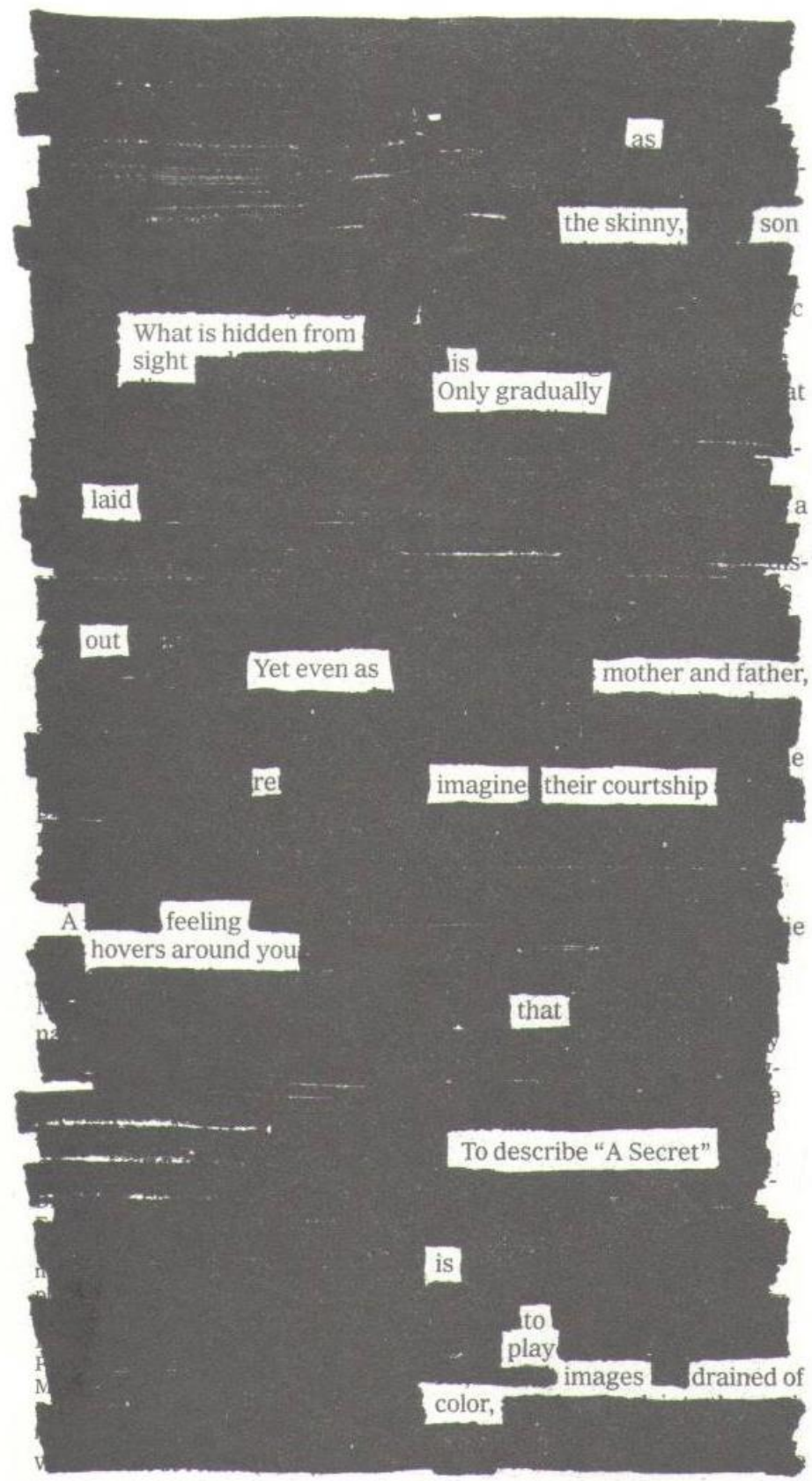


estética do corte nos poemas de Newspaper Blackout, procede-se nesta seção a um close reading de alguns de seus textos, iluminados (ou enegrecidos, a gosto do blecaute?), quando necessário, por algumas reflexões de teóricos e críticos de literatura acerca de escrita e rasura.

Para tanto, toma-se de início o poema "The Skinny Son" (KLEON, 2010, p.61), o qual é reproduzido na Figura 1. Este é composto segundo o procedimento geral descrito no livro: Kleon toma uma seção de jornal formatada em coluna dupla, recorta a matéria e, sem lê-la com atenção, passa os olhos rapidamente pelo texto, selecionando substantivos e verbos que lhe evoquem uma imagem poética. Em seguida, lê mais detidamente o material, em busca de palavras de outras classes gramaticais, como artigos, preposições e conjunções, a fim de construir uma mensagem sintaticamente coerente. Selecionados os termos que comporão o poema, o autor corta o que não lhe interessa na notícia original, valendo-se de canetadas horizontais com um pincel atômico negro de ponta grossa.

Além da óbvia relevância das palavras que permanecem legíveis após o blecaute gráfico, também é significativo o traço da rasura. Na maioria dos poemas do autor, o rabisco vai de fora a fora na página, deixando apenas algumas palavras e lexias à mostra. Em torno destas, criam-se pequenas molduras retangulares, as quais dão destaque a esses vocábulos e lhes conferem dimensão artística enquanto poema, ao passo que seriam rapidamente consumidos e descartados na leitura do gênero notícia de jornal. Esse efeito ilocutório declarativo (AUSTIN ${ }^{8}, 1976$ ) da moldura, capaz de tornar arte o que é prosaico, está na base da estética de Kleon e da arte contemporânea que se vê nos museus, por vezes feita de materiais comezinhos e corriqueiros (DANTO $\left.{ }^{9}, 2006\right)$. A diferença, porém, é que na blackout poetry a moldura não é simplesmente acrescida em torno da obra, como caixilho, chancela ou ornato. Ela constitui a própria obra, pois o apagamento de algumas palavras à caneta é justamente o ato que instaura a moldura das demais.

Tal ideia está presente também na imagem construída pelos elementos verbais do poema. Este é metaforizado pelo filho magricela (The Skinny Son), tomado como primeiro elemento de um símile (articulado pela conjunção as) que o compara a "What is hidden from sight [and] is only gradually laid out". Segundo tal leitura, tanto o esquálido menino quanto o poema passam da condição do invisível ao visível por um processo gradual. Considerando ainda que ao magricela se supõe faltar algo, como alimento (em oposição à forma não pejorativa "magro"), é também por uma ausência que este poema em blecaute se dá a ver. Na materialidade poética, não se trata, claro está, de

\footnotetext{
${ }^{8}$ AUSTIN, John Langshaw. How to Do Things with Words. Oxford: Oxford University, 1976.

${ }^{9}$ DANTO, Arthur. Após o fim da arte. A arte contemporânea e os limites da história. São Paulo: Odysseus, 2006.
} 
falta de comida, mas sim de falta de palavras, as quais foram cortadas, ou barradas, pela rasura do artista.

O jogo entre ocultar e revelar que compõe o poema na folha de jornal é ainda mais significativo ao tomarmos skinny em sua polissemia. Se o uso mais comum do adjetivo é como denotador de magreza excessiva, por outro lado sua derivação do substantivo skin ("pele", em português) justifica outras acepções previstas em dicionários: "resembling skin" (MERRIAMWEBSTER $^{10}$, 2016) e, como substantivo, "inside information" (OXFORD ${ }^{11}$, 2016). Assim, tanto o menino magricela quanto o poema rasurado gradualmente desvelam sob a pele (superfície do corpo ou da página) uma informação que está por trás (da epiderme ou da tinta do pincel atômico). O próprio verbo frasal laid out ("exibir" ou "dispor", em português), núcleo da dialética entre esconder e mostrar no plano do conteúdo, replica essa dinâmica no plano da expressão, uma vez que as duas partes que compõem essa locução não estavam unidas do texto original na notícia. Antes da intervenção de Kleon, o verbo laid (particípio passado de lie) e a preposição out não estavam articulados sintaticamente, como se nota a partir da disposição espacial de ambos no poema. No entanto, por meio do corte perpetrado a caneta, uma relação sintático-semântica insuspeita foi revelada - ou criada - entre os termos que compunham o inventário vocabular da notícia, de maneira algo análoga ao que dissera Jakobson acerca de a poesia instalar, por meio de metáforas e metonímias, uma hibridação das dimensões sintagmática e paradigmática do discurso (JAKOBSON ${ }^{12}, 1971$ ). Considerando ainda que estas são tradicionalmente descritas como os eixos horizontal e vertical da linguagem, a tópica verticalizada entre laid e out no poema, em lugar da justaposição horizontal que se espera na escrita, já é uma transposição visual do sintagma para o paradigma, por meio do corte de todas as palavras que havia entre esses dois termos.

À tremeluzência entre o branco e o preto, o grafado e o barrado, alude também o final do poema como "a feeling [that] hovers around you", em que o verbo hover, ao significar "flutuar ao vento, ou tremular", indica uma oscilação, como a que se dá entre o visível e o invisível na blackout poetry. E o sentimento que paira, nessa imagem, é o de que "To describe 'A Secret' is to play images drained of color". Nesse contexto, tanto a inundação escura de certas partes da notícia quanto a manutenção a seco (drenagem da cor e do negrume?) de outras passagens revelam o poético ('A Secret') que habitava em potência um suporte tão prosaico como o jornal, aguardando apenas uma operação de corte. Escrever torna-se, pois, não um criar, mas revelar mais à frente no tempo (ao fim das rasuras) algo que já havia mais atrás (desde a

\footnotetext{
${ }^{10}$ MERRIAM-WEBSTER. Disponível em <https://www.merriam-webster.com>. Acesso em 07 dez 2016.

${ }^{11}$ OXFORD DICTIONARIES. Disponível em <https://www.oxforddictionaries.com>. Acesso em 07 dez 2016.

${ }^{12}$ JAKOBSON, Roman. Linguística e comunicação. São Paulo: Cultrix, 1971.
} 
impressão do jornal), escavando o "já lá no seu signo", bem aos moldes do que afirma Derrida ${ }^{13}$ :

Se a escritura é inaugural, não é por ela criar, mas por uma certa liberdade absoluta de dizer, de fazer surgir o já lá no seu signo, de proceder aos seus augúrios. Liberdade de resposta que reconhece como único horizonte o mundo-história e a palavra que só pode dizer que: o ser sempre começou já. Criar é revelar, diz Rousset (DERRIDA, 2009, p.15).

Tal movimento dialético entre o texto verbal e a rasura, produção lírica por escrita de um poema ou escavação de uma notícia, está presente também nas reflexões de Barthes sobre a Semiologia, quando o autor afirma que a Semiosis é uma das forças da literatura:

O signo - pelo menos o signo que ele [o semiólogo] vê - é sempre imediato, regrado por uma espécie de evidência que lhe salta aos olhos, como estalo do Imaginário - e é por isso que a semiologia (deveria eu precisar novamente: a semiologia daquele que aqui fala) não é uma hermenêutica: ela pinta, mais do que perscruta, via di porre mais do que via di levare. (...) Chamaria de bom grado "semiologia" o curso das operações ao longo do qual é possível — quiçá almejado - usar o signo como um véu pintado, ou ainda uma ficção (BARTHES ${ }^{14}, 1994$, p.40).

No fragmento de Barthes, a discussão toma vias epistemológicas sobre como o signo, aos olhos do semiólogo, não é um dado anterior à interpretação que ele apenas acessaria por meio da hermenêutica. Em vez disso, trata-se de um "véu pintado, ou ainda uma ficção", na condição de interpretação construída pelo semiólogo a partir de "uma espécie de evidência que lhe salta aos olhos". Para opor essas formas de abordagem do signo, o autor francês vale-se de duas metáforas retiradas do tratado De statua, de Leon Batista Alberti, que entendia a escultura com materiais "moles", como argila e cera, per via di porre ("por deposição", em português); e a com materiais "duros", como a pedra, per via di levare ("por remoção", em português). Segundo a lógica do polímata renascentista, ao modelar com substâncias macias, o artista adiciona porções de massa a que ele vai dando forma; já ao esculpir o mármore, o granito, ou rocha que o valha, o artista arranca de dentro do mineral uma forma que já lhe habitava em potência.

É, pois, per via di levare que Kleon extrai seus poemas de notícias de jornal, ainda que o faça a canetadas, e não a camartelo e cinzel. O tema da subtração destaca-se em diversas outras composições suas, como, na Figura

\footnotetext{
${ }^{13}$ DERRIDA, Jaques. A escritura e a diferença. São Paulo: Perspectiva, 2009.

${ }^{14}$ BARTHES, Roland. Aula. São Paulo: Cultrix, 1994.
} 
2, "Skinny-Dipping" (KLEON, 2010, p.21), cujo título pode ser livremente traduzido para o português como "mergulho sem roupa".

Desde o título do poema, a dialética entre o coberto e o descoberto comparece, uma vez que à nudez e à visibilidade implicadas pela falta de roupa opõe-se a ocultação da pele sob a água, do mesmo modo como as letras de notícias de jornal submergem sob a caneta do poeta. Mas a essa dimensão da submersão soma-se outra, ensejada pela função conativa que abre o texto

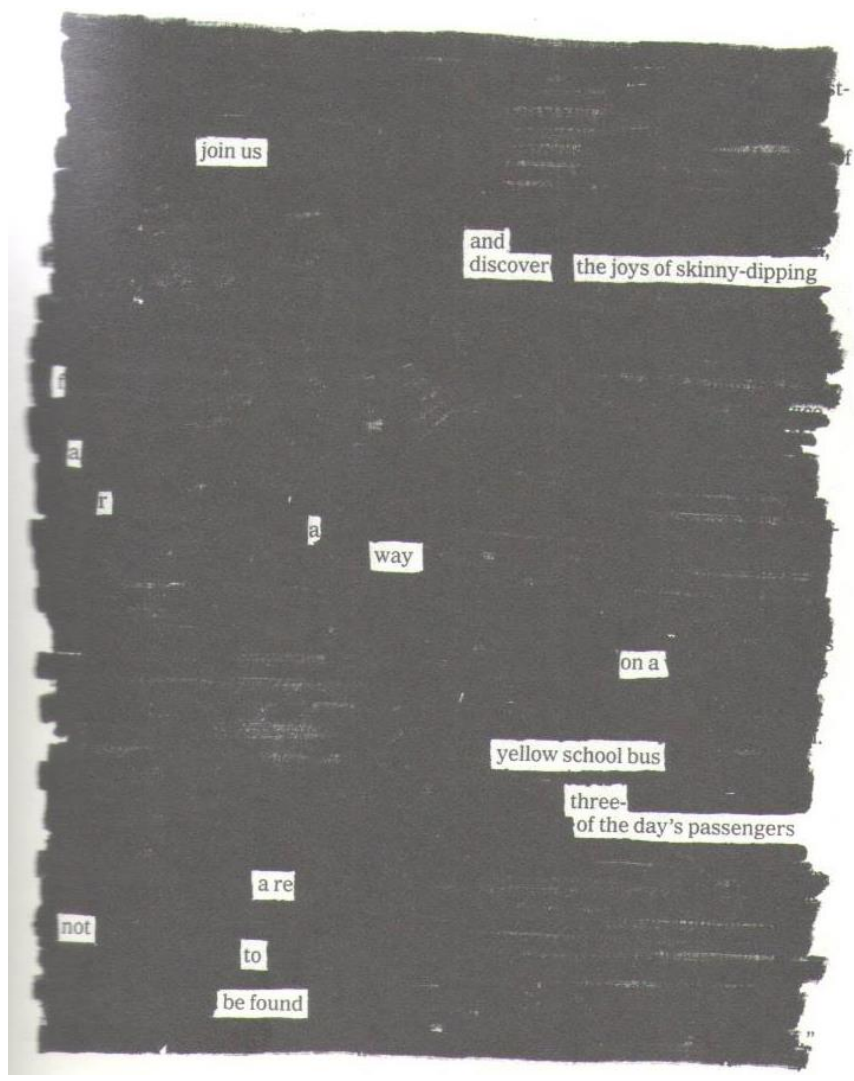

Figura 2: "Skinny-Dipping"

Fonte: Kleon $(2010$, p.21) quando o eu-lírico convida o interlocutor a se juntar a um "nós" (us) no mergulho despido, ainda que não defina com clareza em que corpo d'água ou fluido este se daria.

Tal jogo de esconder e revelar é, além de imagem estruturante do poema, um procedimento formal da blackout poetry que, à dimensão da pilhagem textual, acrescenta a sensual nudez dos banhistas pelados que se veem turvos sob a água, algo análoga à perversão sexual do voyeurismo do leitor (BARTHES $\left.{ }^{15}, 2006\right)$. Assim, a escrita por rasura de Kleon lança-se, entre espaços brancos e manchas negras, como flutuação de significados e significantes nunca finalmente captados por aquele que lê, ainda que de olhos fixos no

corpo do texto (ou dos banhistas) ou convidado para juntar-se àqueles que mergulham. Quando ao desnudamento, é elucidativa a fala de Barthes sobre o strip-tease da bailarina:

O lugar mais erótico de um corpo não é lá onde o vestuário se entreabre? $\mathrm{Na}$ perversão (que é o regime do prazer textual) não há "zonas erógenas" (expressão aliás bastante importuna); é a intermitência, como o disse muito bem a psicanálise, que é erótica: a da pele que cintila entre duas peças (as calças e a malha), entre duas bordas (a camisa entreaberta, a luva e a manga);

\footnotetext{
${ }^{15}$ BARTHES, Roland. O prazer do texto. São Paulo: Perspectiva, 2006.
} 
é essa cintilação mesma que seduz, ou ainda: a encenação de um aparecimento-desaparecimento (BARTHES, 2006, p.15).

Transgressão e intermitência, o poema estruturado como explicitação da rasura (e consequente ocultação do rasurado) se despe diante do leitor e mantém sempre algo escondido e excitante, que potencializa a etimologia de "obsceno", como o que está "fora da cena", tal qual a genitália da bailarina despida ou os trechos da notícia barrados e não mais recuperáveis. Dentro e fora, aparente e invisível, o chiaroscuro das palavras e frases roubadas ao jornal opera como différance no âmbito da blackout poetry, desestabilizando mesmo o tradicional entendimento da composição lírica como arte per via di porre.

A esse respeito, é interessante notar como também a distinção entre différence e différance (DERRIDA, 1972) só pode ser vista como alternância e tremeluzência, tal qual o sexo no strip-tease relatado por Barthes e as palavras cortadas na poética de Kleon. Figuração na ausência, a mancha negra é ao mesmo tempo um signo e o barramento de um signo outro, como na fórmula derridiana da différ/nce, que, no silêncio do talho, contém uma potência semiótica diferinte e diferida.

Em consonância com os jogos de ausência e presença, caros a toda prática intertextual, "Skinny-Dipping" traz no seu bojo uma flutuação também sintática: assim como as palavras do poema pertencem ao mesmo tempo a este texto e à notícia, o sintagma adverbial far away pode integrar tanto a imagem do mergulho quanto a do ônibus amarelo. Afinal, são igualmente gramaticais as estruturas "join us and discover the joys of skinnydipping far away" e "far away on a yellow bus". A ambivalência do sintagma adverbial - cujo sentido de distância se materializa no espaçamento de suas letras, arrancadas a diferentes palavras da notícia - abre diversos caminhos à interpretação. A própria espacialidade, operador semiótico por excelência da poesia visual, põe-se em xeque nas alternâncias entre perto e longe que o poema evoca, de forma parecida com os paradoxais três passageiros que, porque mencionados, estão presentes no poema, mas, porque ausentes, não podem ser encontrados no ônibus escolar amarelo. Talvez estejam, como outras palavras da notícia, apenas escondidos sob o véu de tinta.

Tal qual o espaço, o tempo também é posto em questão como coordenada da sintaxe visual conforme se vê na Figura 3, no poema "Remembering Is Reliving" (KLEON, 2010, p. 7). Na condição de experimentalismo artístico, sugere a última parte do poema: "I am set to start the experiment". A perquirição estética de tal experimento se dá como reencenação motivada por um relembrar que também é reviver, conforme anuncia o título. 
A experimentação abordada no poema, mais do que programática ou científica, ganha ares de misticismo ao trazer algo de volta (na polissemia do verbo "reviver" como recordar ou ressuscitar) por meio de uma invocação, indicada pelo verbo summoning. Só que, em vez de uma pessoa ou uma criatura, a conjuração poética parte da seguinte máxima: "the act of summoning a where is to recreate a when".

Tomar o tempo e o espaço como instâncias que possam ser invocáveis por rituais místicos ou estéticos é já pouco usual, uma vez que pressupõe uma improvável situação anterior à invocação destituída de espaçotemporalidade. Por sua vez, a dicção poética intensifica ainda mais o estranhamento da operação quando trata espaço e tempo não como categorias $a$ priori como no modelo de Kant $^{16}$ (1980), e sim por meio da substantivação dos advérbios interrogativos where e when. Utilizar artigos antes de tais advérbios, além de contrário à sintaxe da língua inglesa, implica uma paradoxal determinação do indeterminável, visto que à especificação do artigo opõe-se

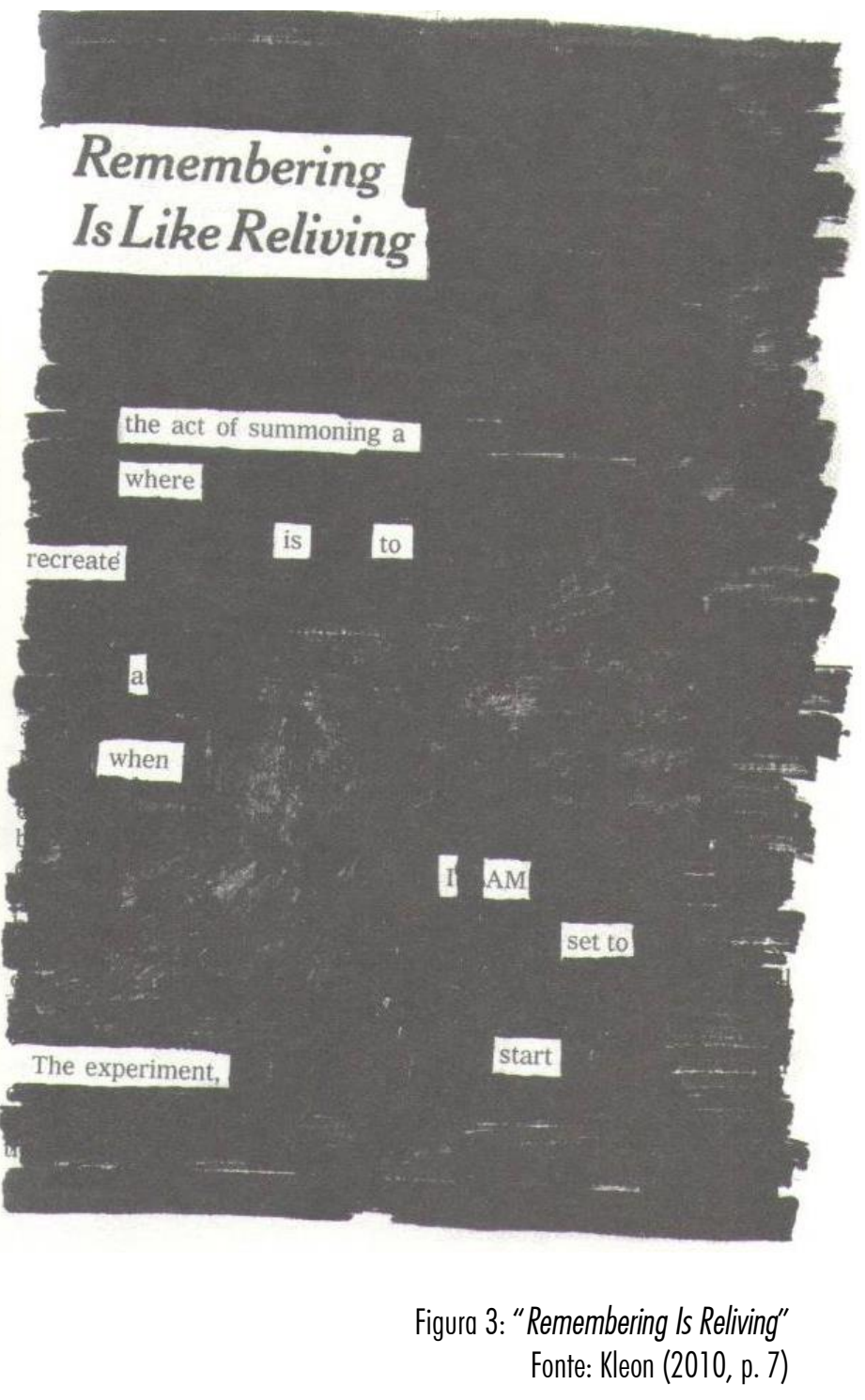
$a$ indefinição indexical do onde e do quando. Então, não mais como categorias filosóficas ou dimensões fenomenológicas, espaço e tempo ganham concretude no poema, em uma materialidade da palavra que não pode ser dissociada na noção de moterialisme, ou materialisme du mot (LACAN $\left.{ }^{17}, 1976\right)$.

Feita coisa, e não mais discurso, a palavra na blackout poetry é devolvida à sua condição material de traço gráfico sobre o papel, o qual pode

\footnotetext{
${ }^{16}$ KANT, Immanuel. Crítica da razão pura. São Paulo: Abril Cultural, 1980.

${ }^{17}$ LACAN, Jacques. L'insu que sait de l'une-bévue s'aille à mourre. Séminaire XXIV. Paris: Seuil, 1976.
} 
ser destacado ou encoberto pela tinta do pincel atômico, a depender das escolhas do artista. Nesse processo, passam a conviver textualidades de tempos e espaços diferentes na mesma página - a notícia de jornal impressa outrora na casa de máquinas e o poema de Kleon, rasurado a posteriori em sua escrivaninha. O produto final da arte do poeta dá notícia (com o perdão do trocadilho) de ambos os tempos e espaços por meio de sua rasura, a qual instala, superpondo camadas de tinta, um palimpsesto entre textos de gêneros assaz distintos. E, se convencionalmente entendemos a poesia visual como campo das semioses espaciais, a partir de diferentes ocupações da superfície bidimensional da página, o palimpsesto de Kleon aprofunda essa noção, fazendo da blackout poetry um objeto estético tridimensional. Como terceira dimensão, o tempo comparece em sua obra por meio da différance entre a notícia e o poema, materializado na rasura que distancia as situações de enunciação de ambos os textos coexistentes na página.

Poética de risco (sinônimo de rasura, mas também do perigo e do temor que as significações movediças evocam), a produção de Kleon dialoga subversivamente com o que se convencionou chamar de pilhagem, contrabando ou plágio, enquanto operações de transtextualização. O próprio autor afirma que "The poems in this book exist thanks to petty crime, writer's block and the Internet" (KLEON, 2010, p.xiii), ratificando a leitura de sua produção poética como transgressão.

A temática da apropriação indébita estrutura também o poema "The Lot" (KLEON, 2010, p.54), visto na Figura 4, em que o eu-lírico narra uma experiência pretérita de invasão ao território alheio, nomeado como the lot no título da composição.

As várias acepções que lot, como substantivo, pode adquirir em inglês, entre "lote de terra", "quinhão" e "destino", denotam que a invasão de que trata o texto se opera em diferentes níveis discursivos. No plano do enunciado, trata-se de entrada não autorizada em território alheio, desconsiderando uma placa de no trespassing ("não ultrapasse", em tradução livre para o português). Conforme se lê no poema, por estar vazio o terreno não ocorreu ao eu-lírico e àquele(s) que o acompanhava(m) tentar manter segredo da invasão, uma vez que não parecia haver quem se importasse.

Já no plano da enunciação, pode o poema conotar a própria invasão de Kleon no texto do jornal, tomando de assalto o discurso alheio para apossarse de algumas das palavras que lá havia. Nesse sentido, é o lote de palavras, frases ou letras que se usurpa ou enegrece, o que acaba por destituí-lo de visibilidade e, portanto, esvaziá-lo, tornando-o um empty lot. Em vez de ocultar o delito editorial, o autor não faz dele segredo ("didn't even try to keep it a secret"), publicando Newspaper Blackout, best seller que desdenha da ideia de no trespassing ao discurso de outrem. O metapoema encerra-se, inclusive, 
com a estrutura someone else's property, referendando a leitura da apropriação indébita que aqui se propõe.

Contudo, não pode ser ignorado o fato de someone else's property não ser de fato um sintagma no texto original, e sim produto de uma subversão discursiva de Kleon, o qual cancela parte significativa de uma frase da notícia para conectar sintaticamente o desconexo. Assim, é só pela rasura do texto da notícia que esta tem algum valor como propriedade alheia; é apenas ao ser

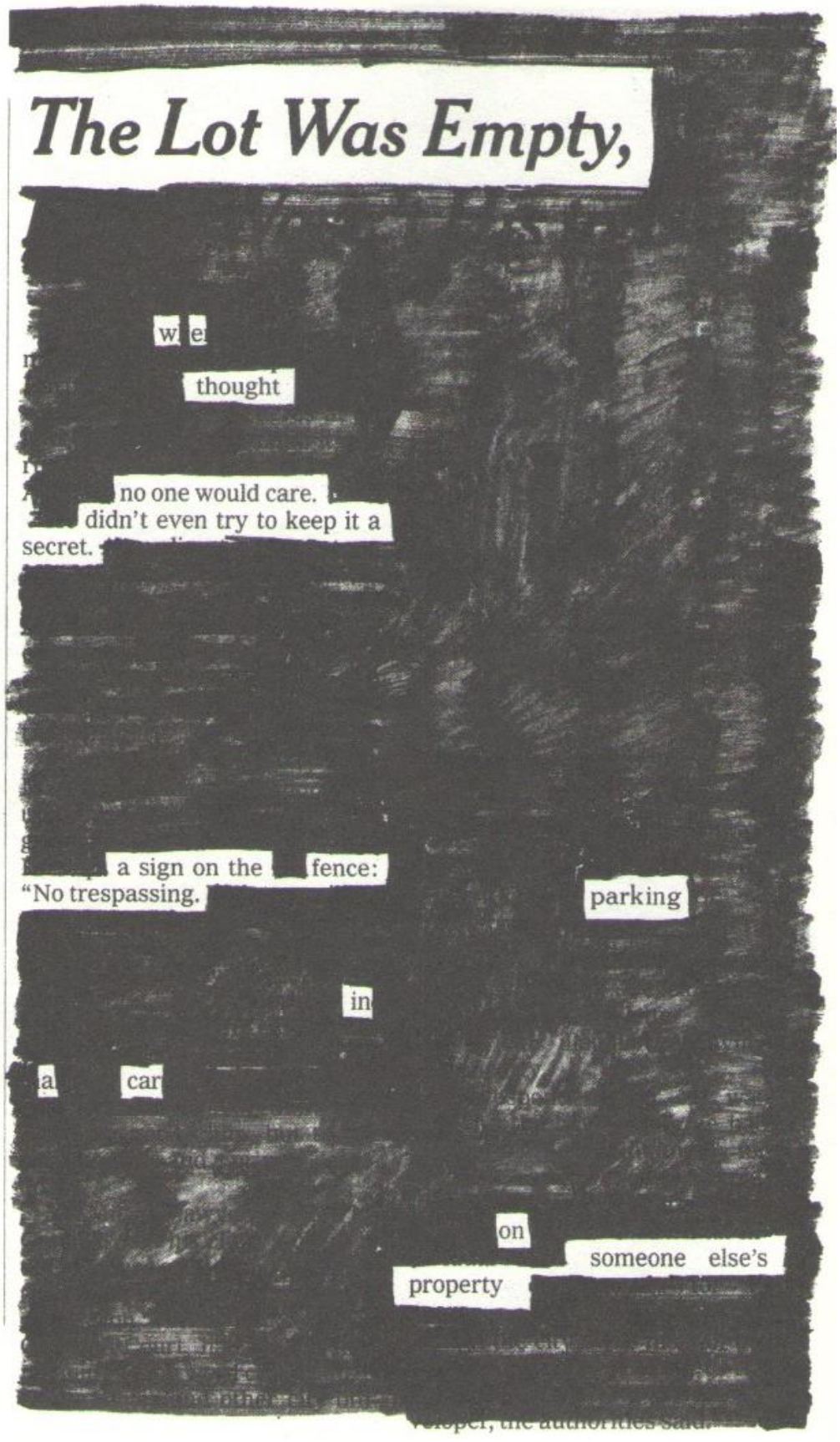

Figura 4: "The Lot"

Fonte: Kleon $(2010$, p.54) subvertida e tornada ilegível, porquanto rabiscada, que a notícia ganha nova vida discursiva. Do contrário, tratar-se-ia de texto esquecido no passado e abandonado à pilha de jornais velhos, como tantos outros lots no jornal que se esvaziam porque não mais lidos.

Tal concepção da escrita poética como crime e invasão ressignifica a própria noção de falta, ratificando sua polissemia como ausência e infração. Assim, composta a partir de um corte a tinta, que impõe partes faltosas a um texto primeiro, blackout poetry é delito também semiológico, em que o escritor devém proscritor, na medida em que proscreve partes do texto jornalístico a uma eterna vida de trevas $e$ ilegibilidade. Proscrever torna-se, portanto, proescrever, em uma escrita 
(des)construtiva, que refabrica o discurso alheio ao mesmo tempo em que o saqueia.

Nessa refabricação de um novo corpo textual a partir de partes de um corpo anterior, revisitam-se, como metalinguagem, mitos da criação profana de monstros a partir de retalhos de cadáveres humanos, imagem estruturante do poema "Monster" (KLEON, 2010, p.52), que se vê na Figura 5.

Claro está que o título do poema define que o monstro em questão tem papel central na composição. Mais interessante é pensar que, além disso, o tamanho da fonte usada no sintagma a Monster denota a centralidade da imagem teratológica não só no texto de Kleon, mas também na notícia de onde este foi extraído. Afinal, as letras grandes no texto original indicavam que o monstro em questão figurava já na manchete do jornal.

Chamando atenção do ponto de vista gráfico, o monstro poético (ou o poema monstruoso?) reedita a etimologia de monstrum, em latim, como aquele se mostra. No plano do enunciado, trata-se de monstro que habita um caliginoso bosque, mas não assusta a personagem feminina que, frente à criatura sombria, "shows a grin as if she's having the time of her life". Seu gozo, mais do que a despeito do monstro e das trevas, parece se dar por causa do monstro e das trevas, que lhe causam o largo sorriso (tradução livre para grin).

Também no nível da enunciação o poema se constrói como arvoredo enegrecido a tinta (em que woods, que designa tanto bosque como árvores, passa a conotar metonimicamente o papel de jornal que delas é feito). Nas clareiras desse bosque,

Figura 5: "Monster" Fonte: Kleon $(2010$, p.52)

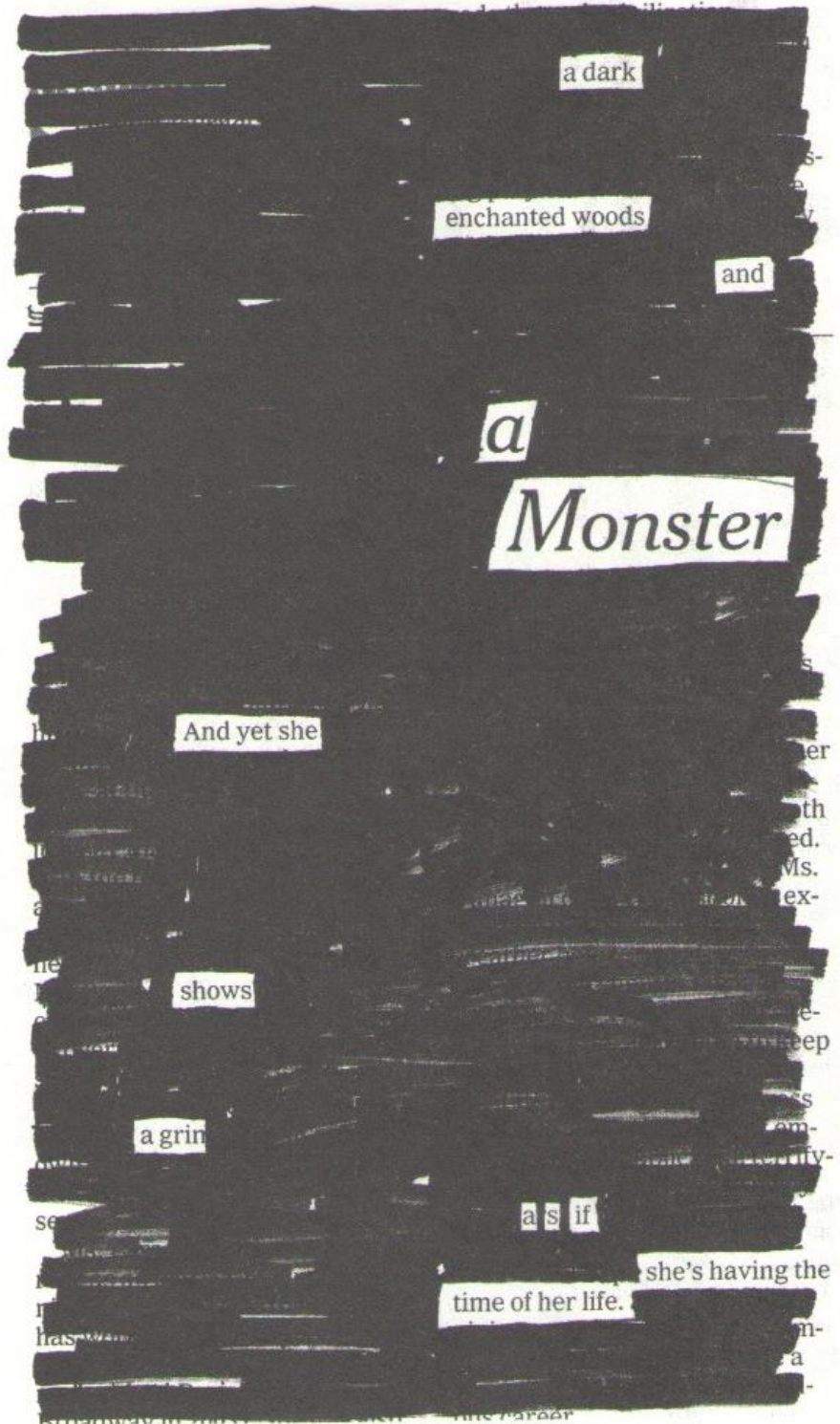


delimitadas pelas molduras entre as palavras do poema, lê-se sobre o monstro que, por definição, ataca, devora, saqueia - todos verbos que podem ser atribuídos a Kleon quando pilha os textos de jornal. O monstro não estaria, pois, apenas dentro do poema, senão também ao lado dele, como sugere a conjunção aditiva em "a dark enchanted woods and a monster". Articulados por parataxe no nível sintático, o monstro e o bosque acabam pareados como o poeta e o poema, enquanto entidades que coexistem no mundo real em que a criação é feita. A ela que olha o bosque de trevas e vê o monstro, e a nós que miramos a floresta de palavras enegrecidas e vemos a monstruosidade literária (no sentido de transgressão e pecado, que envolve sempre a origem dos monstros) cabe apenas rir: não há medo ou ojeriza suscitada pela blackout poetry. O escuro, nesse caso, faz rir pela derrisão com que rasura nossos entendimentos sobre a produção literária.

\section{Considerações finais}

Na seção "How to Make a Newspaper Poem", perto do final de seu livro, Kleon faz alusão a uma célebre imagem de William Carlos Williams (apud MACGOWAN; LITZ18, 1988), retirada do poema "Asphodel, That Greeny Flower": "It is difficult/to get the news from poems/yet men die miserably every day/for lack/of what is found there". A tal dificuldade de encontrar notícias em poemas, o autor de Newspaper Blackout opõe a facilidade com que encontrou poemas nas notícias.

Para além do jogo de palavras e de engenhosa intertextualidade promovida pelo escritor nesse comentário, ganha destaque a ideia de encontrar poemas dentro das notícias, como se estes já habitassem potencialmente os textos jornalísticos. Sob essa perspectiva, a arte de Kleon não consistiria em escrever poemas, mas sim em revelá-los ao ajustar os olhos do leitor para o que sua negra moldura enquadra.

Interessante é pensar que, nesse contexto, a revelação que o artista perpetra não é da ordem da luz, e sim da treva, com uma caneta que enegrece partes do texto primeiro, tornando-o significante opaco e ilegível, ao mesmo tempo em que sua visibilidade (enquanto contraste com o branco da página) aumenta. Cortando a tinta parte significativa do texto original, instaura-se por meio da rasura uma poética per via di levare, em que a mancha preta é índice da escavação que o texto sofre.

Ao passo que Mallarmé tanto dissera do branco da página, como condição de significação dos traços negros ali deitados, Kleon inverte o jogo

\footnotetext{
${ }^{18}$ MACGOWAN, Christopher; LITZ, A. Walton. The Collected Poems of William Carlos Williams. Volume II 1939-1962. New York: New Directions, 1988.
}

92| E N S A I O S 
instalando seu blecaute. Passa, pois, a rasura preta a estruturar a semiose entre o que se mostra e o que se esconde, como palimpsesto de jornal e poema em que lemos apenas os retalhos do corte a tinta.

Recebido em 14/12/2016

Aprovado em 13/08/2017 